\title{
An Empirical Study on Improving the Learning Effect of Physics Experiment Course in High School by Simulation Experiment Software
}

\author{
Xiulin Ma, Yujuan Jia*, Chenyu Fan, Xue Jiang \\ Faculty of Education, Beijing Normal University, Beijing, China \\ Email: maxl@bnu.edu.cn, ^jyujuan8807@163.com, ssfanlmz@163.com, jx19981115@163.com
}

How to cite this paper: Ma, X. L., Jia, Y. J., Fan, C. Y., \& Jiang, X. (2021). An Empirical Study on Improving the Learning Effect of Physics Experiment Course in High School by Simulation Experiment Software. Open Journal of Social Sciences, 9, 309-331. https://doi.org/10.4236/jss.2021.911023

Received: October 26, 2021

Accepted: November 27, 2021

Published: November 30, 2021

Copyright $\odot 2021$ by author(s) and Scientific Research Publishing Inc. This work is licensed under the Creative Commons Attribution International License (CC BY 4.0).

http://creativecommons.org/licenses/by/4.0/

(c) (i) Open Access

\begin{abstract}
Physics experiment course in senior high school plays a very important role in cultivating students' scientific thinking and scientific inquiry ability. However, in teaching practice, due to large experimental error, poor demonstration effect and lack of experimental conditions, it cannot achieve the expected teaching effect. This study integrates the simulation experiment software into the physics experiment classroom in senior high school, in order to optimize the experimental teaching quality and promote the development of students' inquiry ability. In this study, 45 students from class 5 and 47 students from class 6 of grade 1 in a high school in Beijing were selected as the experimental class and the control class respectively. The demonstration experiment of "synchronous satellite orbit transfer launch" and the exploration experiment of "uniform linear motion" were carried out with the help of simulation experimental software. The results showed the teaching based on simulation experimental software plays a positive role in teachers' experimental teaching, reducing experimental errors, improving self-efficacy and teaching performance. On the other hand, limited by the simulation experiment environment, the simulation experiment could reduce the trial and error opportunities of excellent students, and affect the development of students' innovation ability to a certain extent.
\end{abstract}

\section{Keywords}

Demonstration Experiment, Inquiry Experiment, High School Physics Experiment, Simulation Experiment Software, Empirical Study 


\section{Introduction}

\subsection{Physics Experiment Teaching Plays an Important Role in Physics Teaching}

Physics experiment plays an important role in physics teaching, with the feature of intuitive, vivid and visual, which can help students understand the laws of physics and master knowledge better. The new physics curriculum standard also points out that "the inclusion of scientific inquiry in the curriculum content aims to enable students to experience the inquiry process similar to scientific research workers, actively acquire physical knowledge, understand scientific inquiry methods, develop scientific inquiry ability, experience the fun of scientific inquiry, and develop a realistic scientific attitude and innovative scientific spirit" (Ministry of Education of the People's Republic of China, 2012).

Hofstein and Mamlok-Naaman reported in their paper that experiment can help develop students' scientific processing skills, problem solving skills, and draw their attention and develop positive attitudes towards scientific approaches according to objectives of fundamental science education (Hofstein \& Mamlok-Naaman, 2007). Garnett, Garnett and Hackling mentioned that experiment helps students develop their conceptual understandings, application skills and techniques (Garnett, Garnett, \& Hackling, 1995). According to the Association for Experiential Education (AEE), experiential learning is a philosophy and methodology where educators engage directly in motivating learners and reflection is focused on improving knowledge, developing skills (Holtzman, 2011).

\subsection{There Are Still Many Problems in the Traditional Physics Experiment Teaching}

While, there are still many problems in traditional physics experiment teaching. The several reasons for the ineffectiveness of experiment teaching such as the lack of time and planning (Backus, 2005; Booth, 2001; Hackling, Goodrum, \& Rennie, 2001; Jones, Gott, \& Jarman, 2000); large scale courses (Cheung, 2008a; Prades \& Espinar, 2010); teachers' low level attitudes toward experiment, negative perception and beliefs (Brown, Abell, Demir, \& Schmidt, 2006; Cheung, 2008b; Roehrig \& Luft, 2004; Windschitl, 2003); lack of effective and sufficient course materials (Kiviahdem, 2005; Lawson, 2000); challenges related to classroom management (Deters, 2005; Jones, Gott, \& Jarman, 2000); lack of explanation of laboratory security precautions (Deters, 2005; Staer, Goodrum, \& Hackling, 1998). For the teaching practice, most of the experimental operation steps are cumbersome and the parameter configuration is negligible, which causes a fallacious experimental effect. Due to the lack of careful control of the experimental steps and insufficient thinking, some experiments have great errors and fail to meet the expected teaching goals, which makes many students have a strong sense of frustration and fear of doing experiments, and affects their formation of scientific thinking and scientific literacy. In addition, some experiments are too macro or lack of necessary equipment, which will seriously affect the quality of physics teaching. 


\subsection{The Simulation Experiment Software Provides Assistance for Physics Experiment Teaching}

The emergence of a large number of physics-assisted teaching software provides a rich teaching resource environment for teachers to carry out auxiliary teaching. VR technology, as one of the three cutting-edge technologies in the field of information technology, has developed well in the construction of virtual laboratories. In addition, there are many simulation experiment softwares with lightweight features that can meet the needs of classroom experiment teaching and students' exploration experiments. Physics teaching software can be used as laboratory tools during computer assisted experimentation (CAEx) (Zakaria, Phang, \& Pusppanathan, 2019), teaching aids, communication and information tools (Alev, 2003; Beaufils, 2005), a simulator to replace or supplement experiments, as well as modeling and scientific calculation tools (Cox, 2012). For example, "simulation physics laboratory" is a fully open software designed for physics teaching, which provides several object models and specific physical environments. At the same time, a variable editor and a program function programmer are provided for the set physical quantities. As long as the physical model or process can be conceived in the brain, it can be built with the software (Wang \& Wang, 2014). Through the experimental environment constructed by computer modeling technology, simulation experiment software enables people to decompose, delay or pause the experimental process, and provides convenient conditions for students to deeply explore physical phenomena.

\subsection{Research Questions}

This research is based on the teaching practice of the research school and the current information resource conditions, starting from the need to solve the current problems of physics experiment teaching, using "simulation physics laboratory" to carry out physics experiment teaching, exploring the effective mode of simulation experiment software assisting physics experiment teaching and specific effects on core literacy training. Based on this, this research proposes the following research questions:

1) In view of the problems in the traditional high school physics experiment class, what role can the simulation experiment software play?

2) In physics experiment teaching, how to seamlessly integrate simulation experiment software and give full play to its advantages?

3) How does the simulation experiment software integrated with the high school physics experiment play a role in the development of students' core literacy?

\section{Literature Review}

\subsection{The Development of Physics Experiment Course in High School}

From 1902, the Qing Government's Minister of Management Zhang Baixi pre- 
sided over the formulation of the "King Ming School Regulations" to the promulgation of the 2017 version of the "General High School Physics Curriculum Standards", the development of physics curriculum in high schools in China has been more than a century, and physics experiment is an important part of physics curriculum and physics teaching in high schools (Ministry of Education of the People's Republic of China, 2018).

\subsubsection{The Important Position of High School Experiment Course in Physics Teaching}

High school physics experiment is divided into demonstration experiment and inquiry experiment. Demonstration experiment is helpful for teachers to visually guide students' experiments, while inquiry experiment can better reflect students' dominant position than demonstration experiment. It is of great help to cultivate students' creativity, pioneering spirit and innovation consciousness, and greatly improve students' hands-on and brain skills (Tian \& Liu, 2019).

The importance of experiment course in physics teaching is mainly shown in the following four aspects: first, experiment is intuitive, vivid and visual, and it is a purposeful operation behavior, so it can cultivate students' practical operation ability, and good experiment design can cultivate students' interest and stimulate their thirst for knowledge. Second, the experiment provides students with specific physical situations to master knowledge effectively, creates a good learning environment, and enables students to obtain necessary and sufficient perceptual knowledge. Third, the experiment itself is a method of scientific research, allowing students to learn scientific research methods from it. Experiments are an effective way to train students in creative consciousness and scientific methods. Fourth, when students observe and operate experiments, they need not only keen observation ability and proficient operation ability, but also certain analysis and generalization ability, imagination ability, logical thinking ability and so on. Therefore, experiments can cultivate students' abilities, practical and realistic attitude, rigorous and meticulous style and other good scientific quality. Fifth, the development of experimental skills and the mastery of physical knowledge can promote each other, and the mutual knowledge transfer between them is of great significance to cultivate students' innovation ability (Tao, 1996).

High school physics experiment stipulated in the new curriculum standard is not only an important basis of physics teaching, but also an important content, method and means of physics teaching. Researchers have made a good example of integrating experiments into high school classrooms and attracting students to participate in scientific research (Cheng, Gerhard, Gendronand, \& Ziffle, 2019). $\mathrm{Hu}$ believes that in addition to completing the required content of the experimental course, physical experiment teaching also undertakes the objective of optimizing the elements of scientific inquiry and paying attention to the cultivation of students' scientific thinking and scientific inquiry ability (Hu \& Zhang, 2020).

\subsubsection{The Deficiency of Physics Experiment Teaching}

The traditional classroom demonstration leads to the poor effect of the experi- 
ment. Classroom demonstration experiment has always been a common method in physics classroom teaching. However, there are still quite a number of experimental effects are not obvious, such as: shear wave demonstration experiment, when the teacher uses the rope for intuitive teaching demonstration in class, the demonstration phenomenon is not stable, if the hand-held shear wave demonstrator is used to demonstrate, the students only see the particle motion of the simulated waveform, and it does not reflect the real wave process. This affects the effect of demonstration experiment in some cases. For another example, when demonstrating the isochronous experiment of horizontal throwing motion and free falling body motion with horizontal throwing and vertical falling instrument, although the sound of two moving objects landing can be heard at the same time, it is difficult to reflect the isochrony of their motion process, so it is hard to analyze the law of the motion process of two objects.

Students passively participate in experiments and lack the learning spirit of independent inquiry. High school physics experiment teaching has always overemphasized the leading role of teachers, while ignoring students' independent inquiry learning. For example, when students carry out experiments, most of them just follow the experimental procedures prescribed by the teacher, although they can finally complete the experiment smoothly and get satisfactory experimental results. But this kind of experiment actually goes against the purpose and requirements of the experiment. In the process of this kind of experiment, the students' experimental ability, analytical ability and problem-solving ability are not cultivated, let alone the cultivation of exploration spirit and creativity.

\subsection{Simulation Experiment Software and Its Application in Physics Experiment Teaching}

There are many types of simulation experiment software in experiment teaching. Zhang analyzed the necessity and feasibility of using simulation software to carry out physics experiments, and also proposed that assessing students' abilities from the experiment link can stimulate their interests of learning physics simulation experiments (Zhang, 2019). Some researchers proposed by using virtual experiment teaching platform, teaching software and virtual experiment, can have a good teaching effect, better feasibility (Daineko, Dmitriyev, \& Ipalakova, 2017; Li \& Xu, 2015) and can help learners understand physics phenomena better (Bostan, 2011).

Matlab as an easy-to-use scientific computing software has powerful functions such as data acquisition, numerical analysis, matrix calculation, signal processing, data visualization, calculation simulation and graphics processing ( $\mathrm{Li} \& \mathrm{Xu}$, 2015; Zhong \& Zhang, 2010). Anling reproduced the visualization pattern of interference and diffraction through Matlab simulation software (Anling, 2012). The simulation results are completely consistent with the experimental images, which is very beneficial for guiding students' experimental operations. Origin software is another software assist physics teaching, which is simple and easy to 
learn. It has intuitive, graphical, object-oriented window menus and toolbar operations and gradually recognized as the fastest, most flexible, and easiest data analysis drawing software (Huo, 2015). Zeng and Liu took the section of "free falling movement" as an example, using Origin software to analyze and plot the data of the inquiry experiment, and applying modern information technology to assist physics teaching, which can stimulate students' core literacy of physics (Zeng \& Liu, 2019).

The VR virtual laboratory mainly relies on VR technology, which is for human beings to satisfy their increasing desire to explore the objective world (China Institute of Electronic Technology Standardization, 2016). With its augmented reality characteristics, VR technology can project experimental ideas into the real experimental environment. It plays an important role in stimulating students' imagination and innovation vitality. Tsivitanidou, Georgiou \& Ioannouuse the immersive experience of virtual reality to explore learning in physics teaching to understand students' perception and the interactive effect between concept acquisition and attitude characteristics (Tsivitanidou, Georgiou, \& Ioannou, 2021). It has also been applied to some physical experiments and achieved good experimental results (Boettcher \& Behr, 2021; Šiđanin, Plavšić, Arsenić, \& Krmar, 2020; Valdez, Ferreira, \& Barbosa, 2013). However, because VR/AR equipment is usually very expensive, it has not yet been widely popularized for experimental education in primary and middle schools.

\section{Method}

\subsection{Research Context}

Two typical experiments were selected in this study, among which "synchronous satellite orbit change launch" was the demonstration experiment, and the "uniform speed linear motion" experiment was an active and exploratory experiment with students as the main body.

There is a lesson "the application of gravitation artificial earth satellite" in the chapter of "the law of gravitation" in the physics textbook for senior one of the People's Education Edition. Although the principle and application of "synchronous satellite" are not stated in detail in the textbook, the application of "synchronous satellite" often appears in students' exercises, and students are also very interested in the knowledge content of synchronous satellite launch. However, this kind of experiment cannot be demonstrated in kind, and it is difficult to explain clearly only by drawing in the classroom. For this reason, this research selects the demonstration courseware in the resource library of "Simulation Physics Laboratory" to demonstrate and explore the parameters of the three cosmic speeds and their specific modes of action.

The first volume of the high school physics curriculum is a student experiment called "Linear Motion with Uniform Variable Speed". The purpose of this experiment is to verify and study the law of linear motion with uniform speed. The principle of the experiment is to add a fixed external force to a stationary 
experimental trolley, the object starts to move, and the movement of the object is recorded on a paper tape through a dot timer, and then the acceleration of the car is calculated by analyzing the points on the paper tape that record the car's movement. In the traditional teaching mode, the needle type dot timer is used. When the dot timer works, the needle tip dot on the paper tape will form intermittent resistance, which will affect the constant force of moving objects. If we can't guarantee the action of the object under the condition of constant force, the motion of the object is not uniform variable speed motion in the strict sense. However, due to the existence of air resistance and friction, as well as the impact of dot timer, the experimental error is difficult to control, often appear unsatisfactory data, resulting in the experimental effect is not ideal. Therefore, this study introduces the "simulation physics laboratory" software, in the virtual space to create experimental situations, to eliminate the air resistance problems that cannot be overcome under real conditions, so that students can summarize the physical laws through independent exploration and thinking.

\subsection{Participants}

This study selected the students who were enrolled in the first grade (5) and grades (6) of Beijing A high school in September 2016 as the research objects to carry out a one-year study. The numbers of the two classes were 45 and 47 students, and in accordance with the teaching requirements of the first-year physics experiment curriculum in high school, conducted experimental research on the information technology supporting high school physics experiment teaching activities.

\subsection{Research Process}

The purpose of this study is to explore the impact on the quality of teaching on the basis of "simulation physics laboratory" assisted inquiry physics experiment. Based on the "cooperation inquiry" teaching mode, the experimental activity mode is implemented with the process shown in Figure 1.

The above inquiry activities include two aspects of teacher's experimental guidance and students' experimental activities, mainly around the standardized process of experimental teaching.

\subsection{Research Process Control}

In order to ensure the preciseness and scientificity of the research and reduce the influence of non-control factors on the research results, this study follows the following basic norms.

\subsubsection{Premise Guarantee of Research}

1) The experimental class and the control class are taught by the same teacher, the teaching content and the amount of homework are the same, and the total amount of students' learning time is the same;

2) At the first beginning, we conducted a questionnaire survey on the basic 


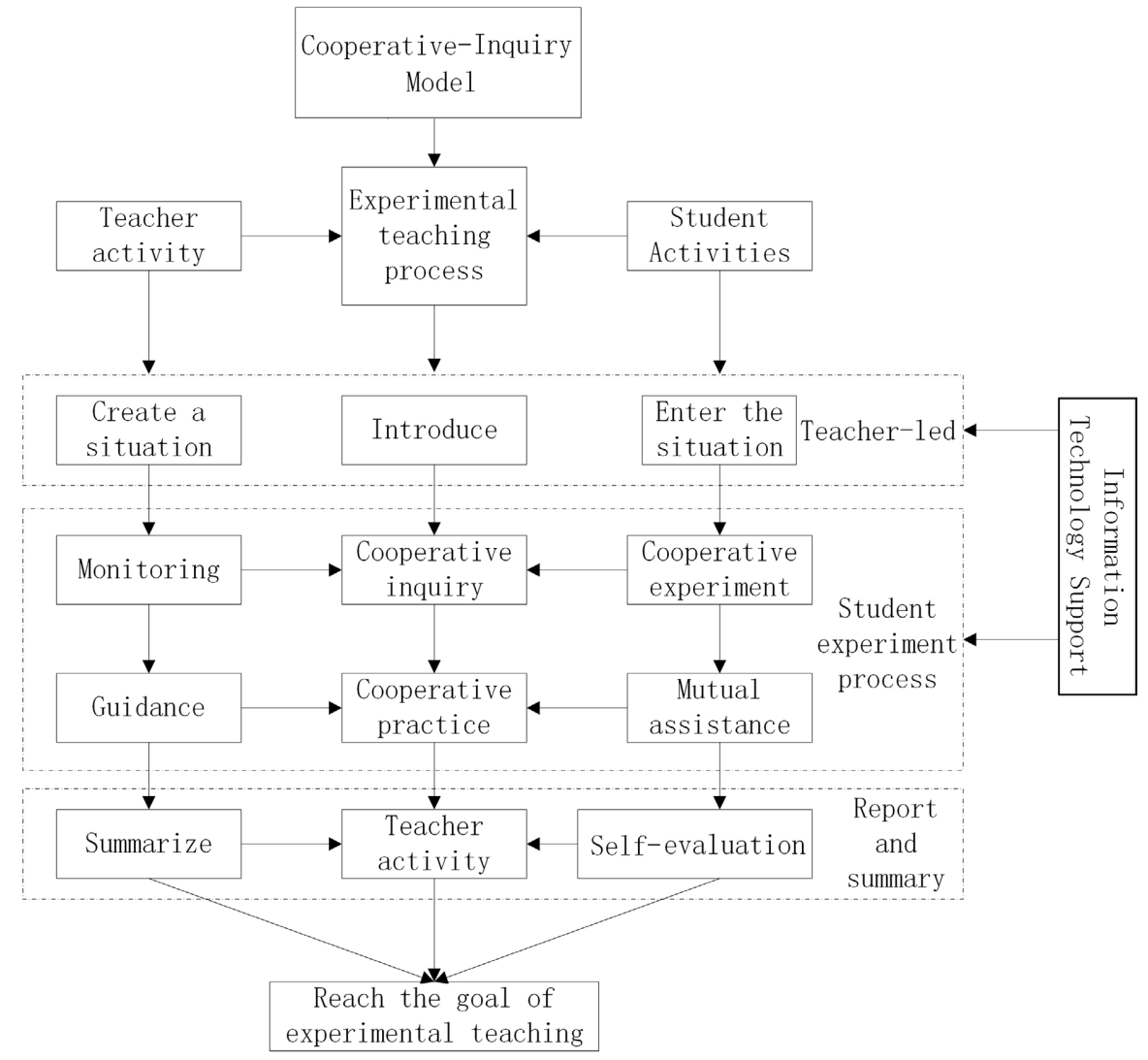

Figure 1. Experimental model.

situation of the students in the two classes, and found that there were no significant differences in the attitude, motivation and self-efficacy of the students in the two classes; from the examination results and entrance examination, there is no significant difference between the two classes.

3) Before the formal start of the physical experiment, the teacher will spend five minutes to introduce the experimental requirements and equipment. Then the students in the experimental class need to use the simulation laboratory software to do 15 minutes of demonstration and exploration activities, and then they can use the real equipment to start the experiment. After listening to the teacher's lecture, the students in the control class can directly enter the experimental link.

\subsubsection{Organize Experimental Activities in Groups}

Both the experimental class and the control class organized experimental activities in the form of group cooperation. In order to ensure the preciseness of the research, the initial learning ability and learning style of the students in the experimental class were investigated before grouping. The evaluation of students' initial ability includes their physics test scores, information technology mastery, and familiarity with the trial of simulation physics laboratory; The analysis of learning style is based on the "students' cognitive style scale" developed by the school of educational technology of Beijing Normal University to evaluate each 
student in order to master the characteristics of their cognitive style.

Considering the requirements of laboratory environment and class reporting time, the author divided 45 students in the class into 8 groups with 6 students in each group, and the last group was 3 students, each group included boys and girls. The composition of the group members is arranged according to the principle of complementary differences in initial ability and learning style. Finally, the group members jointly select a student with strong sense of responsibility and dedication as the leader of the learning group. During the process, teachers need to monitor and evaluate the students' process and give real-time guidance.

\section{Research Process and Teaching Practice}

\subsection{Simulation Demonstration Experiment to Enhance Teachers' Teaching and Students' Desire to Explore}

The software of simulation physics laboratory is used to demonstrate the three cosmic velocities and the working principle of synchronous satellites. Its development process is summarized as: preview before class, report in class, teacher guided questioning, experimental demonstration of speed and surrounding relationship, students' independent experimental exploration and experimental summary.

\subsubsection{Introduction before Experiment}

1) Preview and report

The teacher arranges the preview homework for the students before class. The students should understand the two methods of launching the satellite to the synchronous orbit through independent learning, that is, straight-line launching and orbit changing launching, and compare the differences between the two, and show them in the classroom report.

2) Guide questions and description of the situation

The teacher showed the picture to the students, and made a guiding question to guide the students to think: a) why can the satellite be fixed at a certain point in the sky and not fall down? b) How does this satellite get into orbit and stay stable?

\subsubsection{Pre Demonstration Experiment}

Use the "Simulation Physics Laboratory" software to demonstrate the relationship between the drop location and speed of the parabolic on the ground, so that students can intuitively understand the relationship between the satellite's speed and its trajectory. By setting different parabolic speeds in the software, students can master the physical environment of satellite operation: input different speed parameters of satellite operation, $\mathrm{v}=6.7 \mathrm{~km} / \mathrm{s} ; 7.9 \mathrm{~km} / \mathrm{s} ; 8.6 \mathrm{~km} / \mathrm{s} ; 11.2 \mathrm{~km} / \mathrm{s}$; $15.2 \mathrm{~km} / \mathrm{s} ; 16.7 \mathrm{~km} / \mathrm{s} ; 18.8 \mathrm{~km} / \mathrm{s}$. The students were asked to watch the change of satellite trajectory and demonstrate the relationship between satellite speed and orbit in the pre demonstration experiment. Finally, they observed the phenomenon and found that when the speeds were $7.9 \mathrm{~km} / \mathrm{s}, 11.2 \mathrm{~km} / \mathrm{s}$ and $16.7 \mathrm{~km} / \mathrm{s}$, 
they could show three kinds of motion tracks on the track. The tracks are shown in Figure 2.

\subsubsection{Explore the Working Principle of Synchronous Satellite}

1) How can a geostationary satellite enter the docking orbit?

Teacher asked: what are the basic conditions for a satellite to make a circular motion at a certain height above the ground? Who will provide these conditions?

Student answer: there are two basic conditions for an object to fly in a circle: one is that it needs centripetal force, which is mainly provided by the gravity of the earth on the satellite, that is, universal gravitation. The second is the speed of the satellite in circular flight, which is mainly provided by the rocket engine.

2) A process of orbit change

Guide students to think. Then the teacher made a demonstration in the simulation laboratory. When the satellite is running at the speed of 7.9 kilometers per second, let the students observe the orbit of the satellite; after that, change the speed parameters and do the demonstration again. Let the students observe carefully and make a simple analysis.

3) The second orbit change process

The teacher guides the students to think about how fast the satellite should run in order to maintain its stability? How high should it be? Then the teacher made a demonstration with the simulation laboratory software.

The teacher directly changed the parameters of the satellite and demonstrated the process of the satellite entering the synchronous orbit from the apogee. The results are shown in Figure 3.

\subsubsection{Students' Independent Experiment Exploration}

Students are required to use the "Simulation Physics Laboratory" software to independently change the speed parameters of the satellite to simulate the operation of the artificial satellite, record the experimental parameters and the

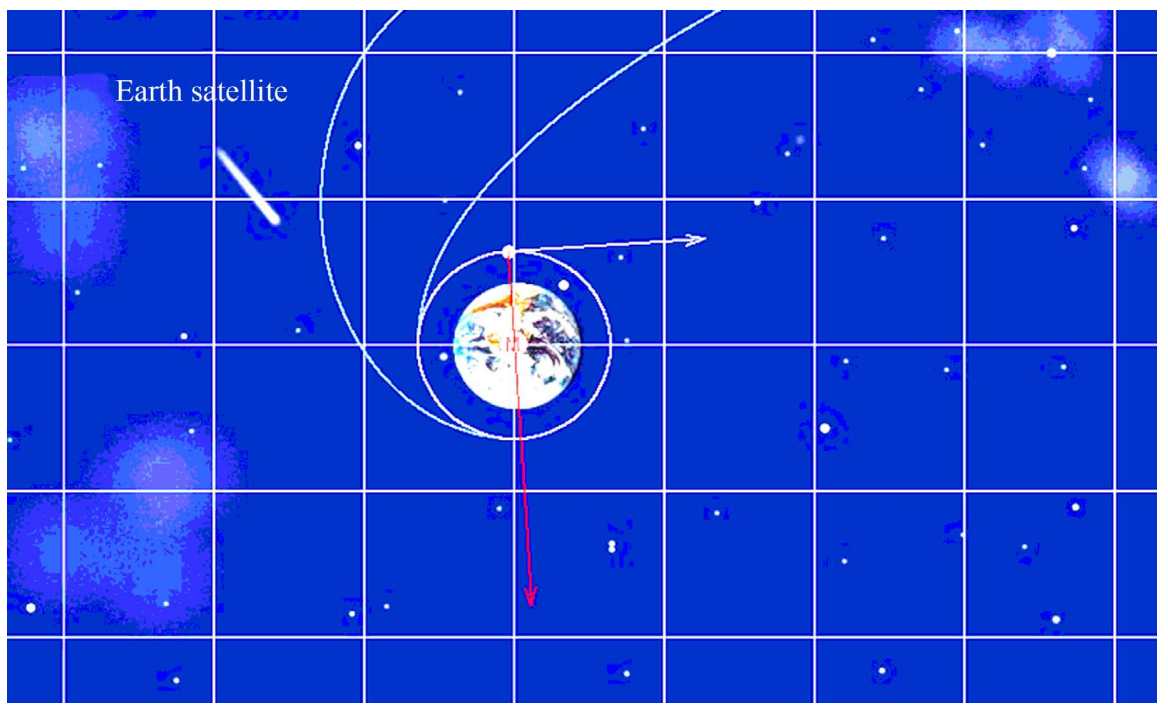

Figure 2. Speed and orbit of artificial satellite. 


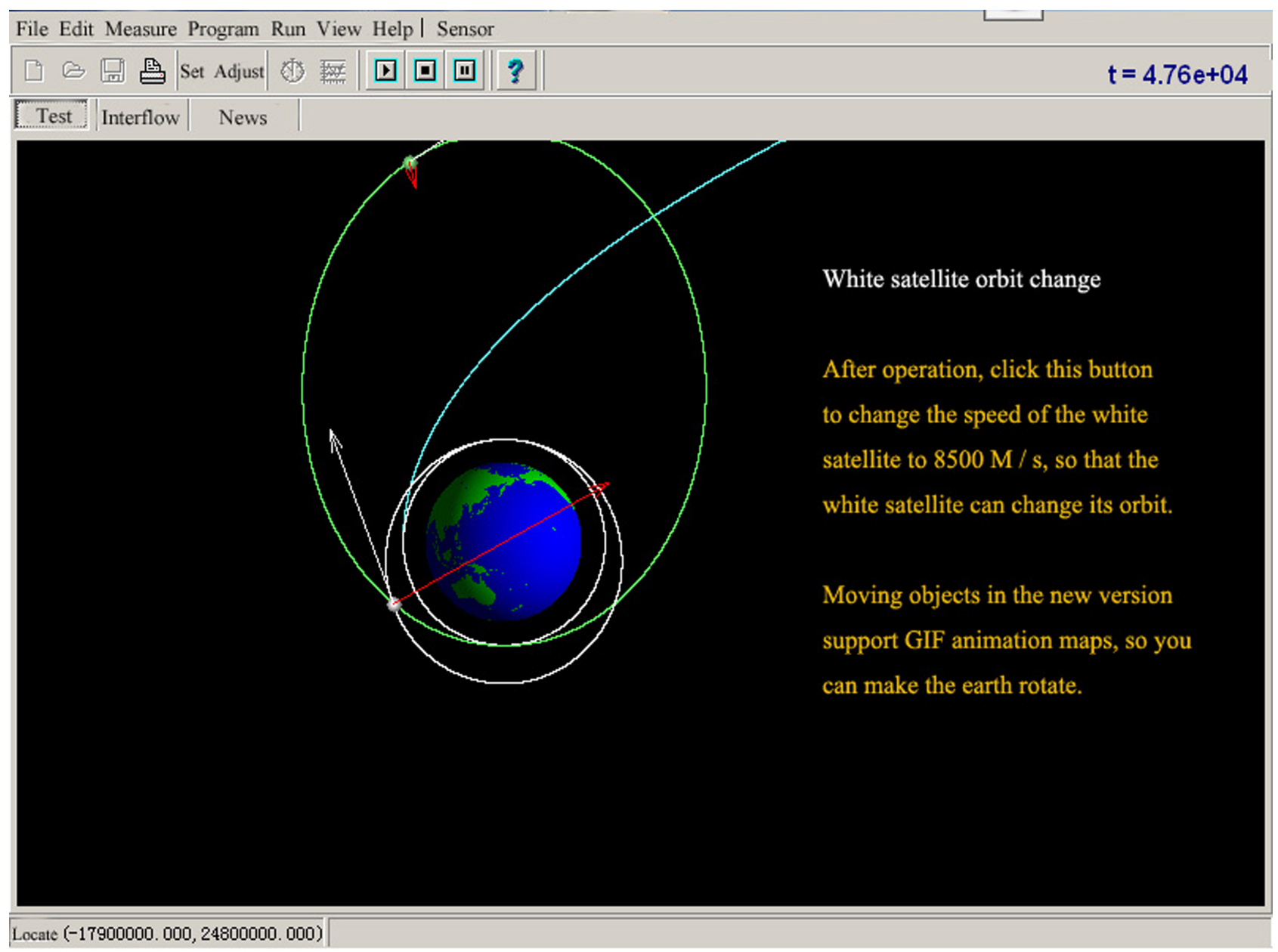

Figure 3. Satellite's orbit change launch.

corresponding effects, and think about the satellite's orbit-changing launch process.

\subsubsection{Experiment Summary}

In the process of demonstration experiment, students only pay attention to observe the phenomenon of the experiment, and lack of specific analysis of the problems. Therefore, teachers often use questions and other ways to guide students to adjust their concerns and guide students to think about the centripetal force of satellite operation and the linear speed of satellite operation, in order to inspire students to combine prior knowledge with current knowledge, and induce students' deep thinking and exploration desire.

\subsection{Simulation Exploration Experiment Aiming at Autonomous Inquiry and Discovery Learning}

"Uniformly variable linear motion" is a very important experiment for the first grade, focusing on the relationship between Newton's second law, acceleration, distance per second and other parameters. In the traditional teaching mode, the movement of the trolley on the slope is mainly recorded by a timing timer. 
However, due to the influence of air resistance, frictional force and intermittent resistance caused by dotting, the displacement value often causes a large error, and it is difficult to present a clear physical law.

This research introduces the "Simulation Physics Laboratory" software in the experiment, creates an experimental situation in the virtual space, eliminates the problems of air resistance, friction and dotting resistance that cannot be overcome under real conditions, and can set parameters at will based on your own assumptions. It is convenient for students to think and summarize the laws of physics through independent exploration.

\subsubsection{Lead in: Teachers Assign Inquiry Tasks}

The teacher asked the students to use the "simulation laboratory" to complete the following experiments, and think about the change law of the displacement value in the process of the experiment. The inquiry tasks assigned by teachers are shown in Figure 4.

Please complete the following settings on the simulation physics laboratory platform:

(1) Add a force of $10 \mathrm{~N}$ to a small ball with a static mass of $2 \mathrm{~kg}$, and the small ball begins to move. Try to analyze the relationship between the displacements S1, S2, $\mathrm{S} 3 \ldots$ in several consecutive and equal time periods from the flash photos of the movement of the small ball?

(if $\mathrm{x} 1 \times 2 \times 3 \ldots$ are the position coordinates of the small ball respectively, $\mathrm{S} 1=\mathrm{x}$ $2-\mathrm{x} 1, \mathrm{~S} 2=\mathrm{x} 3-\mathrm{x} 2, \mathrm{~S} 3=\mathrm{x} 4-\mathrm{x} 3 \ldots$ and so on)

(2) Add a force of $10 \mathrm{~N}, 20 \mathrm{~N}$ and $30 \mathrm{~N}$ respectively to a static ball with a mass of $1 \mathrm{~kg}$, and try to analyze the difference of $\Delta \mathrm{s}$ shown by the movement of the ball on the flash photo under the action of these three different forces $(\Delta \mathrm{S} 1=\mathrm{S} 2-\mathrm{S} 1, \Delta \mathrm{S} 2=\mathrm{S} 3-$ $\mathrm{S} 2, \Delta \mathrm{S} 3=\mathrm{S} 4-\mathrm{S} 3 \ldots$ and so on)

(3) A force of 20 Newtons acts on an object with a mass of $20 \mathrm{~kg}, 10 \mathrm{~kg}$ and $1 \mathrm{~kg}$ respectively. What is the difference between the motion of the small ball and the $\Delta \mathrm{s}$ in the flash photo?

(4) From the analysis of (2) and (3) above, can you find out the law of $F$ and $\Delta s$ ? The law of $\mathrm{M}$ and $\Delta \mathrm{s}$ ?

Precautions:

(1) The quality and force of the ball shall be set strictly according to the values given in the above questions. The flash output display shall be set for the motion of the small ball, and the stroboscopic time shall be set to 0.1 second.

(2) Studentsdesign their own data record form and record data. For the calculation and processing of data, they can use their own calculator or the calculation tools on the computer.

(3) When analyzing flash photos, the location of the initial data point $\mathrm{x} 0$ does not necessarily start from the first ball position taken by the flash photos. It can select any position in the middle as $\mathrm{x} 0$, and the others are $\mathrm{x} 1, \mathrm{x} 2, \mathrm{x} 3 \ldots$ in turn.

(4) Finally, save your own experimental pictures after each group of experiments.

Figure 4. The arrangement of inquiry task. 
In the design of inquiry task, we pay attention to the progressive and guiding of the problem, and try to guide the students to think and summarize the physical laws through the gradual in-depth task.

\subsubsection{The Process of Group Experiment}

The experimental exploration steps of each group mainly include: set questions on the platform and simulate experiments; record data; analysis, calculation and result demonstration.

The facts showed that each group successfully completed the inquiry experiment according to the requirements of teachers.

\subsubsection{Typical Data and Effects in the Inquiry}

1) The process of independent exploration

Preliminary study 1 : after applying $10 \mathrm{~N}$ force to a static $1 \mathrm{~kg}$ ball, the trajectory of the ball is shown in Figure 5.

Further probe 2: after applying $20 \mathrm{n}$ force to a static $1 \mathrm{~kg}$ ball, the trajectory of the ball is shown in Figure 6.

Final probe 3: under the rule of flash time of $0.1 \mathrm{~s}$, the experimental team explored the situation of applying $30 \mathrm{~N}$ force on a static $1 \mathrm{~kg}$ ball with the help of simulation software.

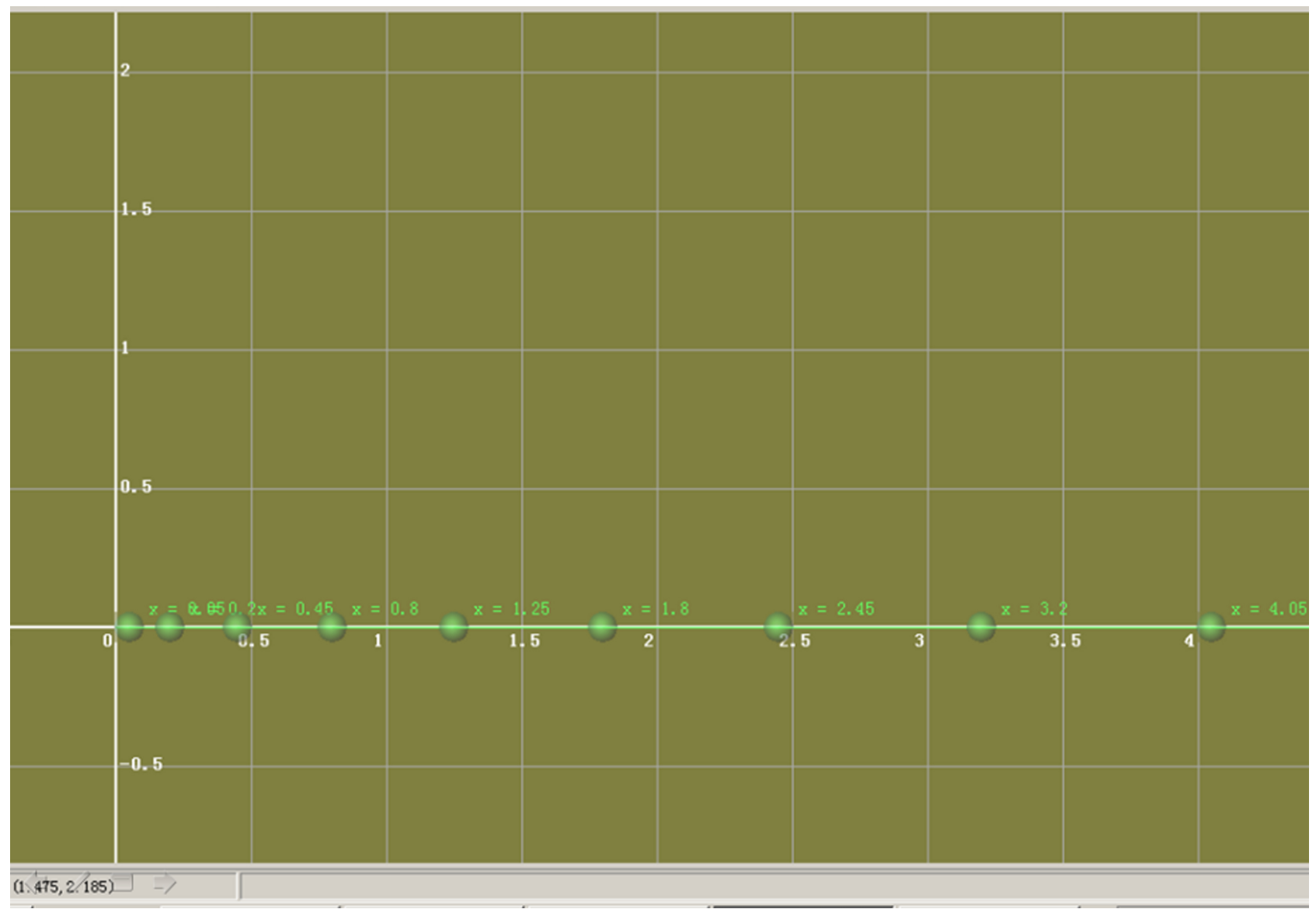

Figure 5. Trajectory of ball (a). 


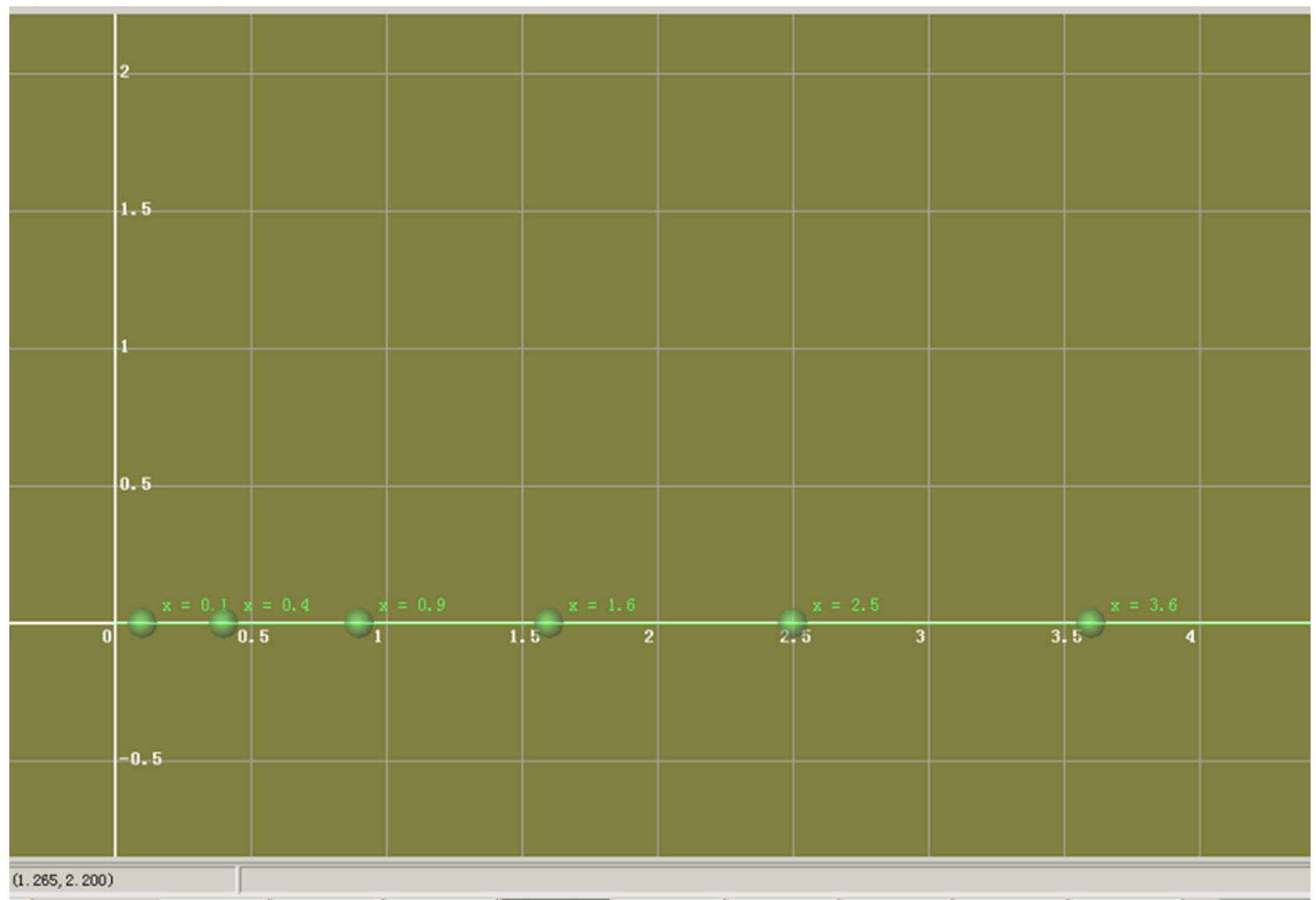

Figure 6. The trajectory of the ball (b).

2) Induction and analysis

After completing the above test, the data as shown in Table 1 is obtained.

Summarizing the data in Table $1, \mathrm{X} 0, \mathrm{X} 1, \mathrm{X} 2, \mathrm{X} 3, \mathrm{X} 4$ and $\mathrm{X} 5$ respectively represent the distance of the ball from the origin every second, and S1, S2, S3, S4 and S5 represent the distance between adjacent balls, the students were surprised to find that the $\Delta \mathrm{S}_{(1,2,3,4)}$ of these three sets of data were constant $0.1,0.2,0.3$, which corresponded to the applied forces of $10 \mathrm{~N}, 20 \mathrm{~N}$ and $30 \mathrm{~N}$, so some students guessed whether $\Delta \mathrm{S}_{(1,2,3,4)}$ is proportional to force $\mathrm{F}$ ?

When some students in Group 5 proposed the conjecture that $\Delta \mathrm{S}_{(1,2,3,4)}$ may be proportional to $\mathrm{F}$ and inversely proportional to $\mathrm{m}$, some students agreed, but some thought it might be an accidental phenomenon, not necessarily a universal law. After discussion, the members of this group unanimously decided to design another two sets of data to verify the above rules.

The results show that with the increase of the force, $\Delta S_{(1,2,3,4)}$ also increases, and the force is proportional to $\Delta \mathrm{S}_{(1,2,3,4)}$; The results show that with the increase of the mass, $\Delta \mathrm{S}_{(1,2,3,4)}$ also decreases, so the mass is inversely proportional to $\Delta \mathrm{S}_{(1,2,3,4)}$.

Teachers guide students to think: 1) What is the meaning of $\Delta \mathrm{S}_{(1,2,3,4)}$ ? 2) What is the relationship between force $\mathrm{F}$ and $\Delta \mathrm{S}_{(1,2,3,4)}$ ? How to narrate and express? 
Table 1. Record of displacement and displacement difference of two adjacent balls (unit: meter).

\begin{tabular}{|c|c|c|c|c|c|c|}
\hline Force $(\mathrm{F})$ & Distance 1 & Distance 2 & Distance 3 & Distance 4 & Distance 5 & Distance 6 \\
\hline \multirow{6}{*}{$10 \mathrm{~N} 1 \mathrm{~kg}$} & $\mathrm{X} 0$ & $\mathrm{X} 1$ & $\mathrm{X} 2$ & $\mathrm{X} 3$ & $\mathrm{X} 4$ & $\mathrm{X} 5$ \\
\hline & 0.8 & 1.25 & 1.8 & 2.45 & 3.2 & 4.05 \\
\hline & $\mathrm{S} 1(\mathrm{X} 1-\mathrm{X} 0)$ & $\mathrm{S} 2(\mathrm{X} 2-\mathrm{X} 1)$ & $\mathrm{S} 3(\mathrm{X} 3-\mathrm{X} 2)$ & $\mathrm{S} 4(\mathrm{X} 4-\mathrm{X} 3)$ & S5 (X5 - X4) & $\ldots$ \\
\hline & 0.45 & 0.55 & 0.65 & 0.75 & 0.85 & $\ldots$ \\
\hline & $\Delta \mathrm{S} 1$ & $\Delta \mathrm{S} 2$ & $\Delta \mathrm{S} 3$ & $\Delta \mathrm{S} 4$ & $\ldots$ & $\ldots$ \\
\hline & 0.1 & 0.1 & 0.1 & 0.1 & $\ldots$ & $\ldots$ \\
\hline \multirow{6}{*}{$20 \mathrm{~N} 1 \mathrm{~kg}$} & X0 & $\mathrm{X} 1$ & $\mathrm{X} 2$ & $\mathrm{X} 3$ & $\mathrm{X} 4$ & X5 \\
\hline & 0.1 & 0.4 & 0.9 & 1.6 & 2.5 & 3.6 \\
\hline & $\mathrm{S} 1(\mathrm{X} 1-\mathrm{X} 0)$ & S2 (X2 - X1) & $\mathrm{S} 3(\mathrm{X} 3-\mathrm{X} 2)$ & S4 $(\mathrm{X} 4-\mathrm{X} 3)$ & S5 (X5 - X4) & $\ldots$ \\
\hline & 0.3 & 0.5 & 0.7 & 0.9 & 1.1 & $\ldots$ \\
\hline & $\Delta \mathrm{S} 1$ & $\Delta \mathrm{S} 2$ & $\Delta \mathrm{S} 3$ & $\Delta \mathrm{S} 4$ & $\ldots$ & $\ldots$ \\
\hline & 0.2 & 0.2 & 0.2 & 0.2 & $\ldots$ & $\ldots$ \\
\hline \multirow{6}{*}{$30 \mathrm{~N} 1 \mathrm{~kg}$} & $\mathrm{X} 0$ & $\mathrm{X} 1$ & $\mathrm{X} 2$ & $\mathrm{X} 3$ & $\mathrm{X} 4$ & X5 \\
\hline & 0.15 & 0.6 & 1.35 & 2.4 & 3.75 & 5.4 \\
\hline & $\mathrm{S} 1(\mathrm{X} 1-\mathrm{X} 0)$ & S2 $(\mathrm{X} 2-\mathrm{X} 1)$ & $\mathrm{S} 3(\mathrm{X} 3-\mathrm{X} 2)$ & $\mathrm{S} 4(\mathrm{X} 4-\mathrm{X} 3)$ & S5 (X5 - X4) & $\ldots$ \\
\hline & 0.45 & 0.75 & 1.05 & 1.35 & 1.65 & \\
\hline & $\Delta \mathrm{S} 1$ & $\Delta \mathrm{S} 2$ & $\Delta \mathrm{S} 3$ & $\Delta \mathrm{S} 4$ & $\ldots$ & $\ldots$ \\
\hline & 0.3 & 0.3 & 0.3 & 0.3 & $\ldots$ & $\ldots$ \\
\hline
\end{tabular}

Note: $\Delta \mathrm{S} 1=\mathrm{S} 2-\mathrm{S} 1 ; \Delta \mathrm{S} 2=\mathrm{S} 3-\mathrm{S} 2 ; \Delta \mathrm{S} 3=\mathrm{S} 4-\mathrm{S} 3 \ldots$ and so on.

\subsubsection{Group Report and Evaluation}

In order to make the experimental learning results of each group have an impact in the whole class and realize the knowledge sharing within the class, two classes are arranged to carry out comprehensive report and discussion when the students' experimental exploration is basically completed.

In this study, quantitative and qualitative evaluation methods were used to evaluate the experiment. In the aspect of quantitative evaluation, it mainly includes four aspects: individual self-evaluation, group internal evaluation, group mutual evaluation and teacher evaluation. Qualitative evaluation is mainly a series of classroom comments, such as the full affirmation of the students' shining points and the correction of their shortcomings in the experimental activities.

\section{Results and Discussion}

In this study, a one-year teaching experiment was conducted in the experimental class. At the end of the school year, the teaching experiment was evaluated, analyzed and summarized. From the three dimensions of students' learning attitude, physical experiment ability and final score, whether the simulation experiment software applied to the experimental class can improve the students' learning effect was analyzed. 


\subsection{The Positive Effect of the Intervention of Simulation Laboratory on Students' Achievement}

This study mainly focuses on the students with learning disabilities who have more difficulties in physics experiments, so the differences in performance are mainly aimed at the students with learning disabilities.

After the implementation of physics experiment teaching, independent sample t-test is conducted for the post-test results of the two classes. The results are shown in Table 2.

Before organizing physics experiment teaching with the aid of simulation laboratory software, there is no significant difference between the test scores of the experimental class and the control class, even the average score of the experimental class is slightly lower than the control class. However, when the simulation laboratory software aided teaching is adopted in the experimental class, the results of the students with learning difficulties in the experimental class have been greatly improved, and there is a significant difference between the experimental class and the control class.

The results show that the average score of students in the experimental class is 72.5 , which is higher than 62.6 in the control class; moreover, the standard deviation of the results of the experimental class is 3.68, which is less than that of the control class, indicating that the students' results of the experimental class are more stable; in addition, the results also show that the proportion of excellent students in the experimental class is also higher than that in the control class. The above results indicate that adding simulation experiment software to physics experiment course plays a very important role in improving students' physics performance, maintaining the stability of students' performance and improving the proportion of excellent students in class. If the test scores are taken as dependent variables, class type as grouping variables, and gender, source of students and other information as covariates, the covariance analysis will also find that the test scores of the experimental class are significantly different from those of the control class. This shows that the proper introduction of simulation laboratory software in physics experiment class has a significant effect on the students who have difficulties in physics experiment class.

Although physics experiment only accounts for about $15 \%$ of students' physics examination, the weight is not high. However, if students can actively use physics experiment learning software to analyze physical laws and physical

Table 2. Test score data after experiment.

\begin{tabular}{lccccc}
\hline & Mean & $\begin{array}{c}\text { Standard } \\
\text { deviation }\end{array}$ & $\begin{array}{c}\text { Proportion of } \\
\text { excellent students }\end{array}$ & $\mathrm{T}$ & Sig \\
\hline $\begin{array}{c}\text { Experimental } \\
\text { class }\end{array}$ & 72.5 & 3.68 & $11.375 \%$ & 12.177 & $0.000^{* * *}$ \\
Control class & 62.6 & 5.11 & $6.317 \%$ & & \\
\hline
\end{tabular}

${ }^{* * *}$ means the result shows there is a significant difference between the experimental class and the control class. 
processes, it will help students fully understand physical laws and truly construct physical models. From the overall score statistics of the semester, it is also found that the students' scores of the experimental class have increased to a certain extent. The physics experiment teaching based on simulation laboratory improves the learning achievement of backward students. At the same time, it also shows that the experimental learning has a positive transfer impact on students' learning of basic physics knowledge.

\subsection{The Intervention of Simulation Laboratory Has a Positive Impact on Students' Learning Attitude}

Based on the data of the experimental class, we can see that the intervention of simulation laboratory has a significant positive impact on students' learning.

\subsubsection{Encourage Independent Inquiry, Cultivate Students' Awareness of Independent Inquiry}

From the performance of the students in the experimental class, the students focus on the classroom presentation from the beginning (that is, only focus on the experimental points and experimental conclusions given by the teacher), and gradually transition to their exploration and trial, and finally the students' active use in solving physics learning problems.

\subsubsection{Improve Learning Interest and Self-Efficacy of Backward Students}

The intervention of simulation experiment software reduces the proportion of experimental failure of students with learning difficulties. Before carrying out the real physical experiment, first launch the experiment with the simulation software to form a stable cognition, and then do the physical experiment based on the real equipment can help students make fewer mistakes and be less blamed. In addition to $50 \%$ of the students who had better physics performance, nearly a quarter of the students with learning difficulties in the experimental class gradually changed from the initial fear of physics learning to the interest in physics learning, and their learning confidence increased significantly. Therefore, the intervention of simulation experiment software can improve the self-efficacy of students with learning difficulties in physics experiment class.

\subsubsection{Affect Students' Thinking Mode of Solving Physical Problems}

According to the results of physics final examination, the methods of solving physics problems of students in experimental class have changed significantly. In the examination questions, there is an operation question that requires students to choose methods to solve physical problems. The final methods given by students mainly include the following five kinds. The results showed that the problem-solving strategies of the experimental class are significantly higher than those of the control class. The statistics are shown in Table 3.

It can be seen from Table 3: first of all, the number of students in the two classes who choose "drawing analysis" and "example calculation analysis" is very high, because this is a common solution that students learn from teachers' usual 
Table 3. Statistics of methods to solve physical problems.

\begin{tabular}{cccccc}
\hline Class & $\begin{array}{c}\text { Drawing } \\
\text { method }\end{array}$ & $\begin{array}{c}\text { Example } \\
\text { of } \\
\text { calculation } \\
\text { and } \\
\text { analysis }\end{array}$ & $\begin{array}{c}\text { Hands on } \\
\text { experiment }\end{array}$ & $\begin{array}{c}\text { With the } \\
\text { help of } \\
\text { physics } \\
\text { learning } \\
\text { software }\end{array}$ & Self-inference \\
\hline $\begin{array}{c}\text { Experimental } \\
\text { class }\end{array}$ & 30 & 18 & 18 & 21 & 2 \\
Control class & 36 & 23 & 11 & 3 & 0 \\
\hline
\end{tabular}

teaching. Secondly, there are obvious differences between the two classes in the item of "using experimental methods", which shows that through the development of research activities, the students' awareness of using experimental methods to solve problems in the experimental class is enhanced. Finally, "with the help of physics learning software" to analyze and solve this problem, the two classes of students formed a sharp contrast, because through teaching activities, almost all the students in the experimental class have the experience of using the physics learning software "simulation physics laboratory", and also realize the advantages of using the learning software to solve problems.

\subsection{The Development and Analysis of Students' Physics Experiment Ability under the Influence of Simulation Experiment Environment}

The investigation of students' physics experiment ability is mainly based on the "Evaluation Scale of Middle School Students' Physics Experiment Ability". After one semester of experimental teaching, the author measured the physics experiment ability of all students in the two classes with this table. The statistical results are shown in Table 4.

It can be seen from Table 4 that the scores of students in the experimental class are significantly better than those in the control class, and there are more students in the high-segment experimental class. By analyzing the causes of this phenomenon, the author thinks that because teachers often use the learning software of simulation physics laboratory to guide students to prepare for experiments, and strengthen the demonstration of experimental operation process and the correction of wrong operation methods, students have stronger control ability and more confidence in physical experiments.

In addition, from the conclusion of the experimental examination, the students in the experimental class are more excellent in the choice of experimental instruments, the standard degree of experimental operation, and the analysis and processing of data.

\subsection{Emerging Problems and Limitations}

With the advancement of simulation experiment software in physics experiment teaching, the author also discovered some new problems, which are not conducive 
Table 4. Distribution statistics of students' final physical experiment ability evaluation.

\begin{tabular}{cccccc}
\hline Class & $95-85$ & $85-75$ & $75-65$ & $65-50$ & Below 50 \\
\hline $\begin{array}{c}\text { Experimental } \\
\text { class }\end{array}$ & 17 & 25 & 12 & 1 & 0 \\
$\begin{array}{c}\text { Control class } \\
\text { Contron }\end{array}$ & 8 & 10 & 21 & 7 & 1 \\
\hline
\end{tabular}

to the realization of the strategic goal of talent cultivation in high school physics experiment teaching.

First of all, in physics experiment class, some students rely too much on simulation software, and even do not want to participate in the experiment in the real experimental environment. They think the experiment can be done better with the help of simulation software, and ignore the cultivation of practical, ability and ability to deal with special situations in the process of real physics experiment.

Secondly, part of the simulation experiment software is not sufficient in the structure and exception handling, which leads to few options for students to explore independently, imprisons students' thinking to a certain extent, and is not conducive to the cultivation of students' divergent thinking ability.

\section{Summary and Reflection}

\subsection{Simulation Experiment Software Plays a Significant Role in Improving Middle School Physics Experiment Teaching}

\subsubsection{Promote the Development of Students' Independent Inquiry Ability}

With the help of the platform of "simulation physics laboratory", the students have a positive performance, which is very gratifying. On the platform, students set the experimental parameters and environmental conditions on the corresponding template. After starting the experiment, it can automatically present the process of object motion change, and can change the parameters and then experiment. Therefore, it is very convenient and efficient to use it to explore some experiments. After the experiment of this teaching activity, the students have a strong interest in using the learning software of simulation physics laboratory, which also has a positive impact on the development of inquiry activities in the information technology environment.

\subsubsection{Reduce the Proportion of Physics Experiment Failure and Improve the Self-Efficacy}

By introducing simulation software into physics experiment teaching, students can systematically preview the whole experiment process and even explore various possible phenomena with the help of simulation software before they come into contact with real physics experiment equipment, which can reduce students' mistakes in the process of participating in real experiments and improve the proportion of successful experiments. Therefore, it plays an important role in reducing the frustration of students with learning disabilities participating in 
experimental activities, and even can improve their self-efficacy to a certain extent.

\subsection{Simulation Experiment Environment Can't Replace Real Physics Experiment}

From the perspective of understanding the laws of physics and students' preview before carrying out real experiments, the simulation experiment environment is of great significance to the reform of physics teaching. However, from the perspective of training students' operation skills, the traditional real environment experiment still has irreplaceable advantages.

\subsubsection{Too Much Dependence on the Simulation Experiment Environment Will Affect the Cultivation of Students' Practical Ability}

The simulation experiment software shows good effect in promoting students to grasp the experimental principle and understand the laws of physics. At the same time, using the platform, students can be guided to carry out the demonstration operation of physics experiment, which can reduce students' damage to experimental instruments due to wrong operation and improve the efficiency of experiment.

However, in physics experiment teaching, excessive reliance on simulation experiment environment deprives students of the opportunity to directly participate in the experiment, which is not conducive to the cultivation of hands-on ability and experimental skills, and is not conducive to students' all-round development.

\subsubsection{The Simulation Experiment Confined to the Simulation Experiment Environment Will Reduce the Chance of Trial and Error for Excellent Students}

The cultivation of innovation ability requires every student to have the opportunity to try and explore independently. Although simulation experiment software provides students with the option of independent exploration in experiment design, this option is limited to the thinking mode of software designers, and has certain limitations. Excessive reliance on the simulation environment will reduce students' chances of trial and error to a certain extent, imprison students' thinking to a certain extent, and affect the development of divergent thinking.

In a sense, no matter how exquisite and complete the simulation software is, it is impossible to achieve the experimental effect in the real experimental scene. In the face of the real experimental scene, the experimental design, experimental effect and experimental phenomenon can never be completely replaced by the simulation experimental environment.

\subsubsection{Not All Physical Experiments Are Suitable for Simulation Experiments}

Through this teaching research, the author also realized that: the development of teaching activities supported by information technology for physical experiment 
teaching must pay attention to the selection of physical experiment teaching content, that is, the selection of teaching content suitable for information technology to play its advantages. Not all physical experiments are suitable to be carried out with simulation experiment software. It is very necessary to cultivate students' practical ability for experiments that can directly observe phenomena.

\subsection{Schools Should Still Pay Attention to the Construction of Laboratories}

The means of information technology cannot replace students' hands-on experiments, especially the development of inquiry activities. When the conditions are met, students should explore in the real scene as much as possible. Therefore, it is necessary to vigorously promote the construction of modern laboratory, minimize the impact of environmental factors on physical experiments, and improve the popularity of students' physical experiment equipment.

\section{Acknowledgements}

We are grateful to Beijing Normal University for embracing this research.

\section{Conflicts of Interest}

The authors declare no conflicts of interest regarding the publication of this paper.

\section{References}

Alev, N. (2003). Integrating Information and Communications Technology (ICT) into Preservice Science Teacher Education: The Challenges of Change in a Turkish Faculty of Education. PhD Thesis, The School of Education University of Leicester.

Anling, W. A. N. G. (2012). Application of Matlab in College Physics Experiment Teaching. Journal of Beijing Institute of Graphic Communication, No. 6, 64-66.

Backus, L. (2005). A Year without Procedures. The Science Teacher, 72, 54-58.

Beaufils, D. (2005). L'ordinateur, outil de laboratoireen physique: Quelles transpositions? Institut national de recherche pédagogique.

Boettcher, K. E. R., \& Behr, A. S. (2021). Using Virtual Reality for Teaching the Derivation of Conservation Laws in Fluid Mechanics. International Journal of Engineering Pedagogy, 11, 42-57. https://doi.org/10.3991/ijep.v11i4.20155

Booth, G. (2001). Is Inquiry the Answer? Science Teacher, 68, 57-59.

Bostan, C. G. (2011). Modelling Physic's Experiments with Yenka Software. In Conference Proceedings of eLearning and Software for Education (No. 2, pp. 421-426). "Carol I” National Defence University Publishing House.

Brown, P. L., Abell, S. K., Demir, A., \& Schmidt, F. J. (2006). College Science Teachers' Views of Classroom Inquiry. Science Education, 90, 784-802.

https://doi.org/10.1002/sce.20151

Cheng, S., Gerhard, D., Gendron, F., \& Ziffle, V. (2019). Incorporation of High-Altitude Balloon Experiment in High School Science Classrooms. Creative Education, 10, 262-272. https://doi.org/10.4236/ce.2019.102021

Cheung, D. (2008a). Facilitating Chemistry Teachers to Implement Inquiry-Based Labor- 
atory Work. International Journal of Science and Mathematics Education, 6, 107-130. https://doi.org/10.1007/s10763-007-9102-y

Cheung, H. Y. (2008b). Teacher Efficacy: A Comparative Study of Hongkong and Shanghai Primary In-Service Teachers. The Australian Educational Researcher, 35, 103-123. https://doi.org/10.1007/BF03216877

China Institute of Electronic Technology Standardization (2016). White Paper on Virtual Reality Industry Development.

Cox, M. (2012). Informatique et apprentissage des sciences: Tendances, dilemmes et conséquences pour l'avenir. RDST. Recherchesendidactique des sciences et des technologies, 6, 23-52. https://doi.org/10.4000/rdst.84

Daineko, Y., Dmitriyev, V., \& Ipalakova, M. (2017). Using Virtual Laboratories in Teaching Natural Sciences: An Example of Physics Courses in University. Computer Applications in Engineering Education, 25, 39-47. https://doi.org/10.1002/cae.21777

Deters, K. M. (2005). Student Opinions Regarding Inquiry-Based Chemistry Experiments. Government Logistics Department. https://doi.org/10.1021/ed082p1178

Garnett, P. J., Garnett, P. J., \& Hackling, M. W. (1995). Refocusing the Chemistry Lab: A Case for Laboratory-Based Investigations. Australian Science Teachers Journal, 41, 26-32.

Hackling, M. W., Goodrum, D., \& Rennie, L. J. (2001). The State of Science in Australian Secondary Schools. Australian Science Teachers Journal, 47.

Hofstein, A., \& Mamlok-Naaman, R. (2007). The Laboratory in Science Education: The State of the Art. Chemistry Education Research and Practice, 8, 105-107. https://doi.org/10.1039/B7RP90003A

Holtzman, R. (2011). Experiential Learning in Washington DC: A Study of Student Motivations and Expectations. Transformative Dialogues: Teaching and Learning Journal, $5,1-12$.

Hu, J. Y., \& Zhang, J. P. (2020). Comparative Analysis of Mechanical Experiments in New and Old Physics Textbooks in Senior High School. Physics Teaching, No. 9, 23-26.

Huo, L. L. (2015). Application of Origin Software in Photoelectric Effect Experiment Data Processing. Value Engineering, No. 33, 182-183.

Jones, M. E., Gott, R., \& Jarman, R. (2000). Investigations as Part of the Key Stage 4 Science Curriculum in Northern Ireland. Evaluation \& Research in Education, 14, 23-37. https://doi.org/10.1080/09500790008666959

Kiviahdem, M. (2005). Effects of Authentic Learning and e-Learning in an Introductory Chemistry Laboratory Course. Nordic Studies in Science Education, 1, 98-98. https://doi.org/10.5617/nordina.499

Lawson, A. E. (2000). Managing the Inquiry Classroom: Problems \& Solutions. The American Biology Teacher, 62, 641-648. https://doi.org/10.2307/4451002

Li, Y. B., \& Xu, Z. H. (2015). Three Methods and MATLAB Realization of Numerical Simulation for Optical Experiments. Physical Experiment of College, 28, 102-105.

Ministry of Education of the People's Republic of China (2012). Physics Curriculum Standard for Compulsory Education (2011 ed.). Beijing Normal University Press.

Ministry of Education of the People's Republic of China (2018). Physics Curriculum Standards for Senior High Schools (2017 ed.). People's Education Press.

Prades, A., \& Espinar, S. R. (2010). Laboratory Assessment in Chemistry: An Analysis of the Adequacy of the Assessment Process. Assessment \& Evaluation in Higher Education, 35, 449-461. https://doi.org/10.1080/02602930902862867 
Roehrig, G. H., \& Luft, J. A. (2004). Constraints Experienced by Beginning Secondary Science Teachers in Implementing Scientific Inquiry Lessons. International Journal of Science Education, 26, 3-24. https://doi.org/10.1080/0950069022000070261

Šiđanin, P., Plavšić, J., Arsenić, I., \& Krmar, M. (2020). Virtual Reality (VR) Simulation of a Nuclear Physics Laboratory Exercise. European Journal of Physics, 41, Article ID: 065802. https://doi.org/10.1088/1361-6404/ab9c90

Staer, H., Goodrum, D., \& Hackling, M. (1998). High School Laboratory Work in Western Australia: Openness to Inquiry. Research in Science Education, 28, 219-228. https://doi.org/10.1007/BF02462906

Tao, F. (1996). Physical Experiment Theory (p. 12). Guangxi Education Press.

Tian, S., \& Liu, M. J. (2019). A Feasibility Study on Incorporating Maker Education into Physics Inquiry Experiment in Secondary School. Journal of Teaching and Management, No. 9, 104-106.

Tsivitanidou, O. E., Georgiou, Y., \& Ioannou, A. (2021). A Learning Experience in Inquiry-Based Physics with Immersive Virtual Reality: Student Perceptions and an Interaction Effect between Conceptual Gains and Attitudinal Profiles. Journal of Science Education and Technology, 1-21. https://doi.org/10.1007/s10956-021-09924-1

Valdez, M. T., Ferreira, C. M., \& Barbosa, F. (2013). Distance Education Using a Desktop Virtual Reality (VR) System. In EAEEIE Annual Conference (EAEEIE), 2013 Proceedings of the 24th (pp. 145-150). https://doi.org/10.1109/EAEEIE.2013.6576518

Wang, Y. K., \& Wang, H. Q. (2014). Real Reproduction of the Construction Process of Situational Simulation "Application of Simulated Physics Laboratory" Software in Physics Teaching. Physics Teacher, No. 1, 62-65.

https://doi.org/10.1088/1475-7516/2014/01/029

Windschitl, M. (2003). Inquiry Projects in Science Teacher Education: What Can Investigative Experiences Reveal about Teacher Thinking and Eventual Classroom Practice? Science Education, 87, 112-143. https://doi.org/10.1002/sce.10044

Zakaria, N., Phang, F., \& Pusppanathan, J. (2019). Physics on the Go: A Mobile Computer-Based Physics Laboratory for Learning Forces and Motion. International Journal of Emerging Technologies in Learning (iJET), 14, 167-183. https://doi.org/10.3991/ijet.v14i24.12063

Zeng, X., \& Liu, J. Z. (2019). Application of Origin Software in Data Processing of Middle School Physics Experiment-Taking the Experimental Teaching of "Free Falling Motion" as an Example. Physics Teacher, No. 9, 74-77. https://doi.org/10.1088/1475-7516/2019/09/022

Zhang, L. (2019). Study of the College Physics Experiment Teaching and Learning Based on Computer Simulation Technology. Physical Experiment of College.

Zhong, K. J., \& Zhang, H. L. (2010). MATLAB GUI Based Optical Experiment. Research and Exploration in Laboratory, 29, 52-53. 